\title{
Información del PH El patrimonio minero andaluz. El futuro de un pasado
}

Lorenzo Cara Barrionuevo

Arqueólogo. Centro Virgitano de Estudios Históricos

\section{Resumen}

El rico patrimonio histórico minero andaluz todavía es poco conocido y valorado. Resultado de una confluencia de experiencias, metodologias e intereses, la arqueología industrial ha permitido iniciar la investigación de sus restos más recientes, sin que por ello podamos disponer todavía de un catálogo completo de los principales conjuntos o instalaciones. Si exceptuamos el Museo Minero de Riotinto, con un alto grado de consecución y funcionamiento, esta dispersión también es reconocible en las iniciativas para su rehabilitación y puesta en valor, en general proyectos localistas con graves problemas de definición y financiación, originados en las propias características de este tipo de patrimonio.

\section{Palabras clave}

\section{Patrimonio industrial}

Patrimonio minero

Minería

Arqueología

Andalucía

Historia económica

Puesta en valor

\section{Introducción}

Despreciado hasta fechas recientes, y hoy todavía amenazado por la ignorancia, el patrimonio industrial es objeto de un verdadero descubrimiento para muchos ciudadanos. En Andalucia, donde las condiciones económicas generales hicieron derivar esta "industrialización" hacia el sector extractivo, la minería constituye una parte importante de su patrimonio cultural e histórico.

A partir del desarrollo en las últimas décadas de la "arqueología industrial" (ARQUEOLOGÍA, 1991 y TICCIH, 1995), el patrimonio minero contemporáneo ha pasado a constituir una importante fuente de conocimiento histórico y un valor patrimonial en alza, con una problemática específica de gestión.

Si la toma de conciencia sobre el valor de estas huellas ha partido de su amortización como restos obsoletos gracias a los cambios tecno-económicos operados, el proceso de su valoración específica (y por lo tanto, la dotación de un contenido histórico concreto) abre nuevas vías para su comprensión y puesta en valor, un camino en el que todavía queda mucho por recorrer.

\section{Patrimonio minero y arqueología}

La valoración de los recursos extractivos como tema de estudio cuenta con una larga tradición arqueológica que gira en torno a la importancia económica de los metales y al significado social que alcanzaron muchos de ellos. Por lo tanto, los lugares de explotación (ya fueran minas o canteras) han merecido cierta consideración por parte de los investigadores.

$>$ La arqueología minera y los paradigmas de investigación

Desde las teorias difusionistas dominantes hasta hace algunas décadas en el ámbito de la prehistoria reciente y la protohistoria, la minería constituía un medio privilegiado para comprender no tan solo la economía (ARRIBAS, A. y otros, 1989) y los intercambios de productos específicos sino también el cambio cultural (BOSCH, P. y DE LUXAN, F., 1935). De hecho, la formación geológica de muchos arqueólogos produjo una temprana atención sobre las minas y los metales (SIRET, H. y L. 1887). Sin embargo, trabajos recientes han rebajado la importancia social de la primera metalurgia (GÓMEZ, P., 1997), con relación a la explotación del silex (RAMOS, A. y otros, 1991).

Como una especialización de la arqueometría destaca la arqueometalurgia, centrada en el estudio de las propiedades físico-mecánicas de los útiles, resultado de las características intrínsecas del mineral, los mecanismos de extracción y la forma de transformarlo en metal (AMORES, F y LLORET, T., 1995), materia de la que ya se va disponiendo de algunas monografías (MONTERO, 


\section{$036-037$ Información del PH}

E I patrimonio minero andaluz. El futuro de un pasado

\section{PH45 - Octubre 2003}

I., 1992 y 1994). En este sentido, cabe afirmar que conocer las características de las menas, sus calidades y usos tradicionales, puede servir para explicar la tipología de las explotaciones (por ejemplo, en la primera mitad del siglo XIX, el plomo de sierra de Gádor se extraía en cuatro calidades; CARA, L., 2002).

Sin embargo, la investigación sobre el patrimonio minero ha alcanzado un nuevo desarrollo en los últimos años como resultado de un doble cambio de perspectiva de estudio. De una parte, las investigaciones han virado de la economía del consumo a la de la producción, centrándose en los lugares, procesos, tecnologías y relaciones sociales de producción (TORRÓ, J., 1994). De otra parte, del estudio del objeto privilegiado se ha pasado a la investigación sobre la "cultura material" y con ella al mundo cotidiano, donde se manifiestan y resuelven las contradicciones entre la producción y el consumo (CARANDINI, A., 1984 y 1997) y es posible rastrear otras "historias paralelas" (THOMPSON, P., 1988).

Hasta cierto punto concomitantes, estos cambios han supuesto la aplicación y consolidación de unas metodologías específicas, que tienen por fundamento la arqueología, y la pareja valoración del mundo minero en toda su complejidad e implicaciones (FRANCOVICH, R., coord., 1993 y 1997). De hecho, estudios integrados recientes han permitido abordar la minería desde un enfoque diacrónico (BLANCO-FREJEIRO, A. y ROTHEMBERG, B., 1981) y extensivo, con un importante componente paisajístico y territorial (OREJAS, A. y otros, 1999) que supone un nuevo aliciente para su puesta en valor.

En este sentido, es evidente que la aportación de la arqueología (y la propia naturaleza de las fuentes o documentos con los que se complementa) será muy distinta según el objeto y las características materiales y funcionales de la instalación o equipamiento pues las huellas de las actividades extractivas desmanteladas pueden dejar menos evidencias ahora que en el pasado.

\section{$>$ La arqueología industrial}

Dentro de la propia flexibilidad del "documento arqueológico" ha sido posible la aparición de arqueología temáticas, entre las que cabe incluir la "industrial" o la "de la arquitectura". La primera ha conocido un desarrollo progresivo en los últimos treinta años hasta su consolidación en la década de los Ochenta, cuando se implanta en España (ARQUEOLOGÍA, 1991 y TICCIH, 1995).

Vinculada desde sus inicios a la defensa del industrial heritage, el proceso de toma de conciencia sobre el valor patrimonial y de identidad colectiva de estas "reliquias" del pasado giró en torno a la catalogación de los edificios y su preservación como un frágil legado.

Como disciplina de estudio se fue abriendo camino entre algunos investigadores del Reino Unido más como objeto que como método de estudio (BUCHANAN, R.A., 1977 y HUDSON, K., 1964). Al carácter localista, nostálgico y sentimental de los pri-
${ }^{1}$ Además de estas aportaciones que tengamos constancia, candiles de época intermedia (siglos XI a la primera mitad del XIII) han sido hallados en algunas minas de Linares y La Alpujarra.

1. Acción minera del levante almeriense (colección del autor) 2. Dibujo del lavadero por flotación de fluorita en Berja (1956)

meros aficionados se fue uniendo el interés suscitado por diversos profesionales. Las aportaciones que ha recibido la "arqueología industrial" de distintas disciplinas (Historia Económica, Social o de la Técnica, Sociología del Trabajo, Antropología Social), justifican tan acusada riqueza y complejidad metodológica que casi cabe definirla como un campo de investigación disperso y confuso.

Digo confuso porque, en principio, poco podría aportar la arqueología (una disciplina nacida en el siglo XIX para conocer el pasado más antiguo del hombre, fundamentalmente, a través de la excavación de sus lugares de ocupación; CARANDINI, A., 1977) con unas instalaciones de las que podemos conservar, incluso, los proyectos de obras, memorias y prolijas descripciones (MADOZ, P., 1845-50) cuando no fotografías y otros formatos documentales.

Pero si nos atenemos, simplemente, a los objetivos y a algunos de los métodos de investigación, las relaciones parecen más estrechas con una disciplina que hace tiempo rompió sus ataduras temporales. Además, la arqueología posibilita partir del análisis concreto de las situaciones reales, un punto al que historiadores COHEN, A., 1987) y antropólogos sociales (CHECA, Fr., 1995), preocupados por modelos de desarrollo o comprensión generales, quizá no estén dispuestos a llegar. En este sentido, hay que tener en cuenta que el concepto (igualmente difuso) de "cultura material" ha rehabilitado la investigación arqueológica entre los historiadores, a veces, más tradicionales (CARANDINI, A., 1997 y FRANCOVICH, R. y MANACORDA, D., eds., 2001).

Incido en el carácter de la investigación porque sólo a través de ella es posible establecer la realidad concreta del bien y destacar sus valores más importantes; es decir, sin investigación no sabremos nunca qué es lo que estamos presentando al público.

Un patrimonio diverso que hay que conocer

Aunque son numerosos los datos históricos (PÉREZ, J.A., 1996) más o menos legendarios sobre la minería prerromana en la región (incluidas algunos interesantes relatos como el de la "Mina del Sabinar" o la "Sepultura del Gigante", en sierra de Gádor; CARA, L., 2002), es en época romana (entre los siglos II a-C y II d-C) cuando encontramos una trama de conocimientos históricos suficientemente amplia, susceptible de materializarse en un sistema patrimonial complejo a partir de algunos restos arqueológicos (DOMERGUE, C., 1987 y 1993).

Los testimonios abarcan desde la famosa Societas Castulonensis o Castulonensium, con sede en esta importante población cercana a Linares (que también controlaba explotaciones en la provincia de Córdoba), hasta datos sobre los sistemas de explotación y las condiciones de trabajo (DOMERGUE, C., 1993), pasando por los procesos tecnológicos aplicados (por ejemplo, el famoso sistema de desagüe de las minas de Riotinto mediante ruedas hidráulicas conservadas en su museo, BLANCO-FREJEIRO, A. y LUZÓN, J. Mª., 1966). 


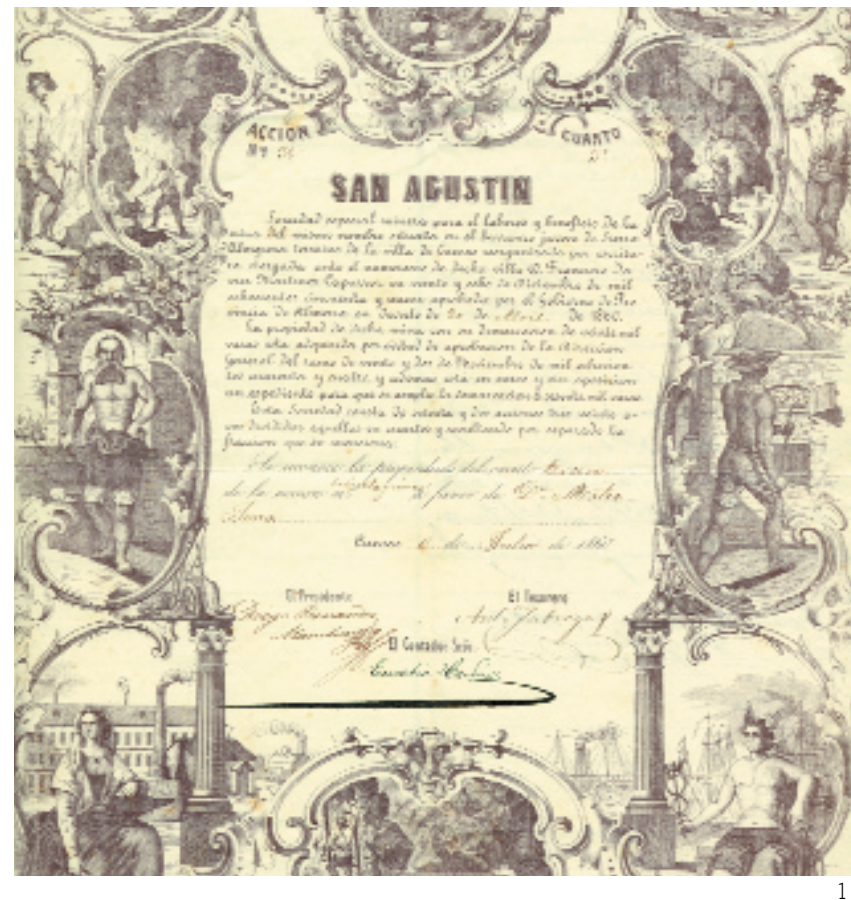

La minería de época andalusí es una gran desconocida, pues hasta el presente los estudios se han centrado en la recopilación de referencias textuales (VALLVE, J., 1996) y la publicación de hallazgos ocasionales (BERNÁRDEZ, M ${ }^{\text {a }} \mathrm{J}$. y otros, 1996) ${ }^{1}$. No obstante, está plenamente atestiguada (por ejemplo, una mina y fundición de Berja era propiedad particular del sultán de Granada y en el beneficio de los antiguos escoriales para dar un baño de "alcohol" o vidriado protector y decorativo a la cerámica; CARA, L. y RODRIGUEZ, J.Ma ${ }^{a}$, 1996). Recientemente ha despertado el interés de los investigadores con resultados prometedores (BERTRAND, M. y otros, 1996).

En la corona de Castilla, las minas constituyeron una regalía, es decir un monopolio que la monarquía aprovechaba a través de diferentes concesiones y privilegios. En el siglo XVI destacan varias actividades extractivas, en las que sobresale Francisco de Cobos, comendador mayor de Castilla, secretario y hombre de la confianza absoluta de Carlos I (SÁNCHEZ, J., 1989). En Almería, se benefició el alumbre, utilizado como mordiente de las fibras textiles (FRANCO, A., 1996), aunque la explotación minera andaluza más importante aparece con las minas de plata de Guadalcanal en 1555, que cierran al poco (GONZÁLEZ, T., 1832 y SÁNCHEZ, J., 1989).

En La Alpujarra, el siglo XVII es un periodo de consolidación (GONZÁLEZ, T., 1832). A partir de 1642 (cuando aparece el estanco o prohibición del aprovechamiento y venta libre del plomo; COLECCIÓN, 1889, 1890 y 1892), se estableció una fundición con varios hornos de pava, alimentados con fuelles, en Presidio (hoy Fuente Victoria). Por desgracia, apenas se han descrito restos materiales de la minería andaluza de este periodo.

La Dirección General de Minas, creada en tiempos de Carlos III, reorganizó la producción en 1748. A partir de este momento, la fundición del plomo se establecía obligatoriamente en las fábricas nacionales de Alcora (1753), Baza, Motril y Turón (1789) y sobre todo en la de Presidio, con una diversificación de la producción de municiones que se expedían por el puerto de Almería a Sevilla, Alicante, Valencia y otros puntos.

La Real Fábrica de Plomos de Alcora (Canjáyar) es la única que se conserva íntegra en toda Andalucía. En su interior, Ios edifi-

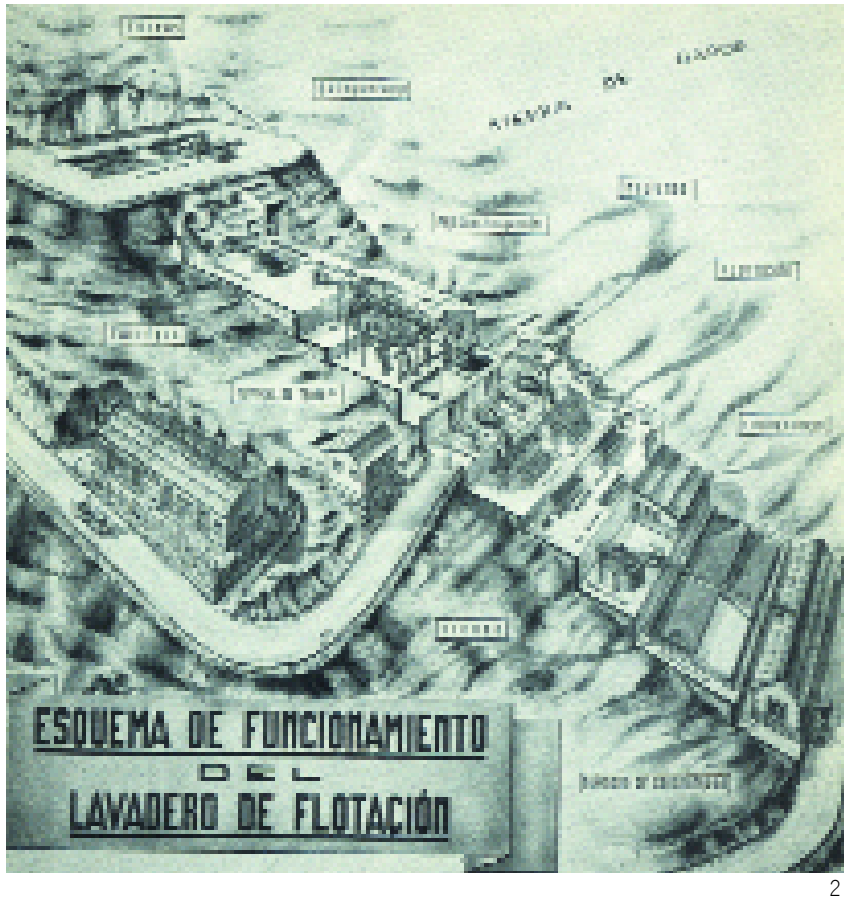

cios se encuentran alineados a lo largo de un patio; entre ellos destacan dos hornos "castellanos" y uno reverbero posterior, más un conjunto de dependencias secundarias y áreas de transformación del mineral (CARA, L., 2002).

Debido a la presión de los mineros de la zona, la nueva ley de 1825 liberalizó totalmente del sector (COLECCIÓN, 1889, 1890 y 1892), algunos años antes de la "liberalización" política. La minería de sierra de Gádor revolucionó a los mercados internacionales del plomo en las décadas de 1820 y 1830 (PÉREZ DE PERCEVAL, M.A., 1985), precisamente cuando la revolución industrial y un importante desarrollo urbano requerían de sus aplicaciones.

Además, aportó una tecnología propia (el horno "reverbero español") capaz de consumir el escaso combustible de la zona y obtener un beneficio hasta del $80 \%$ del plomo. El carácter innovador de esta actividad se percibe cuando la casa comercial malagueña "Rein y Cía" introduce en su fábrica de Adra los primeros hornos reverberos ingleses, alimentados con carbón (1824), e instala una máquina de vapor de 25 CV (1827), convirtiéndola en una de las primeras de España que utiliza esta fuente de energía (PÉREZ DE PERCEVAL, M.A., 1985). Las fundiciones del Peñón de Castala (Berja) y de Heredia (Almería) son algunos de sus ejemplos todavía visibles.

Por aquella época, Marbella lideraba la incipiente industrialización española con las fundiciones de hierro de "La Concepción" y "El Ángel" en Río Verde, mientras empresarios locales levantaban la fundición de plomo "Buenavista" en 1836 (NADAL, J., 1972), cuyas interesantes ruinas aún se conservan.

Hubo también una industria metalúrgica derivada de la mineria, de menor importancia económica y trayectoria más incierta, de la que apenas quedan restos, y resulta, por tanto, peor conocida (por ejemplo, las fábricas de albayalde para pintura o de calamina para latón) o bien se trata de manufacturas más especializadas (MORA, P., 1994).

Mayor grado de concreción histórica y patrimonial presentan las herrerias, cuya importancia en el mundo rural fue grande al abastecer de herramientas, aperos de labranza, clavazón (im- 


\section{$038-039$ Información del PH}

E I patrimonio minero andaluz. El futuro de un pasado

\section{PH45 - Octubre 2003}

prescindibles, por ejemplo, para puertas, mobiliario o molinos harineros) y utensilios domésticos a los campesinos.

Aparte de otras menores, conservamos información de las de Bogaraya (entre Almócita y Padules), Bacares (ambas en Almería) y Lugros o Jeres del Marquesado (cerca de Guadix) (LÓPEZ, T., 1985 y 1990). La primera fue fundada en 1517 (CARA, L., 2000) y dio origen a la del Aguilón (Ohanes) en 1824; de ambas se conservan el imponente salto del martinete y otras dependencias (CARA, L., 2002).

Con el descubrimiento de los ricos filones plomizos de sierra Almagrera (Cuevas de Almanzora, Almería) en 1839, capital local y extranjero (muy vinculado al vecino coto minero de Cartagena-La Unión y a la ciudad de Almería) se aunaron para desarrollar una metalurgia avanzada y complejos sistemas de desagüe (SÁNCHEZ, A., 1983). Las minas y hornos del Pilar de Jaravía (Pulpí), las fundiciones "Nueva" y "La Invencible", el desagüe de El Arteal o la máquina de vapor de El Chaparral (1873), en Cuevas, constituyen algunos de sus restos más evidentes.

A la decadencia de la minería del plomo almeriense (a partir de los años 1870, y con mayor incidencia desde 1885), le siguió el desarrollo de la del hierro (SÁNCHEZ, A., coordin., 1991). Esta tuvo una expansión tan rápida como su decadencia (de 1885 a 1915). El transporte fue la gran asignatura pendiente por lo que se habilitaron líneas férreas (de Linares Almería, en manos de la "Compañia del Sur de España", para el hierro de Alquife (COHEN, A., 2002), o la de Sierra Alhamilla), cables aéreos (como el de Bédar a Garrucha) y embarcaderos (GÓMEZ, J.A. y COVAS, J.V., 1994), entre los que destaca el de Las Almadrabillas de Almería, proyecto que Harrison y Monche llevaron a cabo entre 1901-1904 (MORALES, R. y GAGO, A., coord., 2001a y 2001b), aun pendiente de rehabilitación.
3. Antigua cabría de Sierra Almagrera (foto: Gabinete Pedagógico Almería) 4. Máquina de vapor de El Chaparral (1878) en Cuevas de Almanzora (foto: Gabinete Pedagógico Almería) 5. Cinta transportadora en Alquife, abandonada en 1996 (foto: autor)
En Sevilla, destaca el complejo siderúrgico de El Pedroso, iniciado en 1817 y con importantes vestigios hasta los años Setenta, y Aználcollar donde se explotaron las piritas de 1876 a 1942.

Colonizada por empresa extranjeras, el desarrollo de la minería onubense despega con fuerza en 1866 para consolidarse con la poderosa "Riotinto Company Limited" que compra al Estado las minas (1873) y construye una línea de ferrocarril. Pero sin duda, la obra señera, es el muelle de embarque, un extraordinaria ejemplo de la arquitectura del hierro, obra de los ingenieros Bruce, Gibson y Ridley (1874) (FLORES, M., 1983 y GIL, L., 1984).

\section{La "tranversalidad" del patrimonio minero}

Las consecuencias del desarrollo minero fueron fundamentales para entender el progreso de la región entre 1815 y 1930. Algunos efectos fueron directos, otros son producto revertido, de larga duración y una inusitada amplitud territorial; todos han interrelacionado de manera compleja y local. De aquí el valor "pedagógico" del patrimonio minero para evidenciar, por ejemplo, las contradictorias relaciones entre historia y medio ambiente.

Al fuerte aumento de habitantes se unió la formación de una burguesia regional con intereses en diversos puntos geográficos y sectores productivos, cuyo prototipo fueron las familias Larios o Heredia de Málaga, muy vinculada esta a Almería (NADAL, J., 1972), o los Orozco (SÁNCHEZ, A., 1983 y 1991). Este capital local fue perdiendo importancia con el auge de la minería del hierro y del cobre (desde 1880), que prácticamente quedó en manos inglesas (FLORES, M., 1983 y GIL, L., 1984).

La cara opuesta de la sociedad minera fue la emergencia de la clase trabajadora de mineros-campesinos (COHEN, A., 1987) y la

\section{La Cuenca Minera de la provincia de Huelva. Su folclor}

\section{Onofre López}

Periodista

Bajando por la parte sur de la Sierra de Huelva nos encontramos con la Cuenca Minera, conocida en estos lugares como El Andévalo, nombre aún no descifrado aunque presenta las hipótesis de referirse a la diosa Ande-Baal, en el término municipal de El Cerro de Andévalo, de clara reminiscencia fenicia, y a la referida de origen árabe, de Ándelos.

Veintiséis son los pueblos que aglutinan esta zona andevaleña -o Cuenca Minera- que, en su aspecto folclórico, sólo presenta ocho localidades que cuentan con un amplio pentagrama musical, que se fue gestando a lo largo de los siglos, como con- secuencia de aquellos encuentros culturales que se producian debido a la trashumancia de ganado, procedente, en su gran mayoria, de las tierras de Castilla y León.

Estas ocho localidades son: Alosno, El Cerro de Andévalo, Santa Bárbara de Casa, Cabezas Rubias, Calañas, Valverde del Camino, Zalamea la Real y Riotinto. Poseen una individual partitura para manifestar su autóctona música, siendo la del Fandango, en sus múltiples variantes, la más popularmente conocida.

De Alosno, situado en la zona central de la provincia, se dice que es la cuna del fandango; que alli nació y se crió, y que fue diversificándose en estilos y formas hasta llegar a poseer el coplero más amplio de todo el mapa fandanguero, a lo que hay que sumar otras muchas músicas diferentes como son las llamadas "Coplas del Niño" (Villancicos), "Saetas antiguas", "Rogativas de lluvia", "Cantos de trilla", "Copla de los quintos", "Romances", "Seguidillas" y "Baile del pino". 

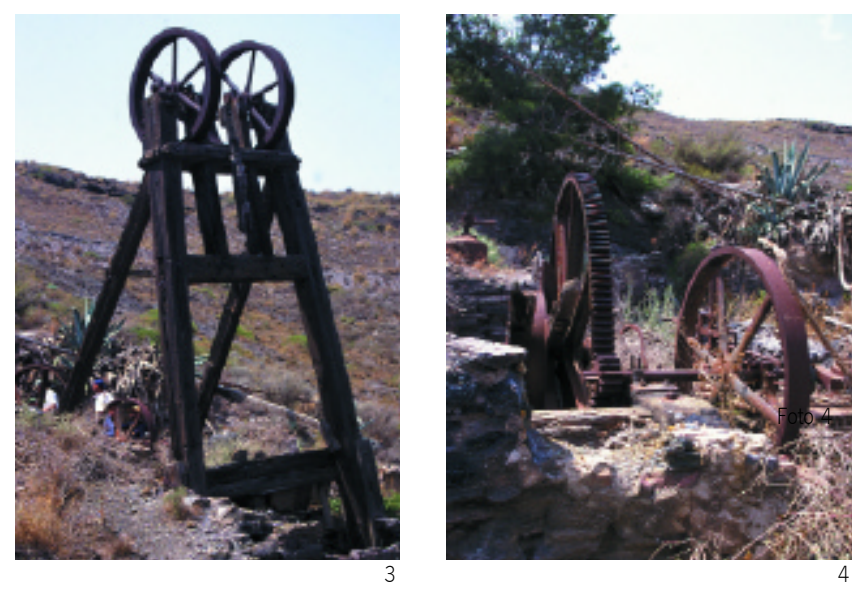

pronta inclusión de ideales emancipatorios de desigual implantación (CHECA, Fr., 1995)

Mientras que gran parte de los beneficios obtenidos en el primer periodo se revirtieron en la construcción y mejora de la vivienda urbana y en el acondicionamiento agrícola (CARA, L., 2002 y RUIZ, A., 2001), la segunda minería generó un modelo de desarrollo "coIonial" (GIL, L., 1984) cuyos beneficiarios fueron los comerciantes y, sobre todo, el capital extranjero que concentró las explotaciones (SÁNCHEZ, A., coordin., 1991). Además, introdujo como elemento singular ciertos gustos sociales y arquitectónicos europeos (en especial ingleses) en la vida doméstica (RAMÍREZ, J., 1985).

La minería también produjo efectos medioambientales devastadores. Una intensa deforestación de los montes y la acumulación de escombreras terminaron por aumentar la erosión del terreno, lo que aumentó la peligrosidad de las riadas (SOBRINO, J., 1994). El ejemplo paradigmático vuelve a ser Almería, donde en 1834 se había acabado con cualquier trazo de bosque en La Alpujarra (SÁNCHEZ, A., 1996). Por su parte, la inestabilidad de escombreras y vertidos ha ocasionado desastres como el de Aználcollar.

El reto de la puesta en valor

A pesar del evidente potencial de ocio cultural (CAPEL, H., 1996) que presenta el patrimonio minero andaluz, se puede afirmar que la política de su puesta en valor ha sido, en gran parte, errática y difusa.

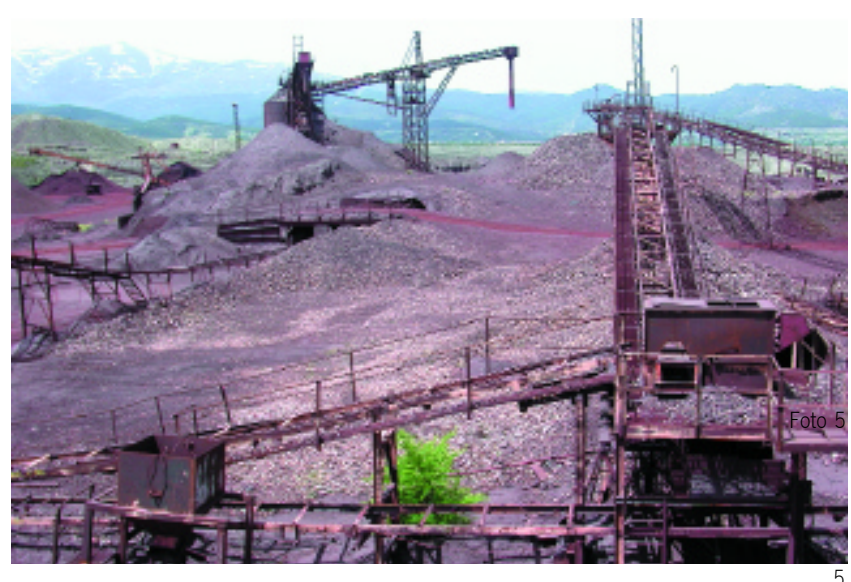

Como siempre, el registro y el inventario son herramientas fundamentales de conocimiento y gestión patrimonial (CATALOGACIÓN, 1996 y IZARZUGAZA, I. y OLAIZOLA, J.J, 1994). Pero, pese a planteamientos pioneros (MARTÍNEZ, A., 1985 y TOMÁS, L., 1994), todavía no se ha ultimado un catálogo sistemático y detallado de instalaciones y conjuntos mineros particularmente significativos de ámbito regional (DOCUMENTACION, 2000).

Bien es verdad que el patrimonio minero se caracteriza por su dispersión y diversidad (pozos con castilletes, cabrias o malacates, escombreras, sistemas de selección, molturaje o preparación, hornos y chimeneas de fundición, almacenes, naves, tolvas, líneas de ferrocarril y embarcaderos, generadores de energía, etc.), por su especificidad (es realmente difícil aplicar propuestas foráneas; GONZÁLEZ-MORENO, A., 1994) y por un fuerte componente medioambiental que permite inscribirlo en corrientes museológicas novedosas.

Además, dentro de los complejos industriales es necesario proceder, nos guste o no, a una doble selección, tanto en su carácter (histórico, cultural, técnico, artístico, emocional, testimonial o práctico) como en su integridad física (por ejemplo, se puede conservar una cabria pero es muy difícil hacerlo con la totalidad de la cadena de extracción), factor este estrechamente vinculado al de la seguridad del visitante, un aspecto que, a menudo, se olvida o minusvalora.

En este sentido, es de gran importancia plantearse seriamente el uso de estos elementos. Dotar de un futuro al pasado debe justificarse
En lo que respecta al Fandango, podemos identificar varios estilos conocidos como "populares" entre los que destacamos el llamado "cané" -que normalmente se canta en grupo-, el estilo "valiente" y el "parao", este último carente de letra alguna, sólo expresado con la gaita y el tambor, y que sirve de ritmo al baile de los "cascabeleros" que acompañan al Patrón, San Juan Bautista, el día de su procesión por las calles del pueblo. En los llamados "personales", Alosno cuenta con una extensa lista de estilos como son los creados por Juana "la Conejilla", Manuel Pérez, Juan María Blanco, Bartolomé García "el de la Tomasa", Manuel Blanco "el Acalmao", Antonio Abad, Juan Rebollo, Juana Maria "la de Felipe Julián" y D. Marcos Jiménez. A todo esto hay que añadir la personal forma de expresar el fandango de Paco Toronjo, reconocido como el gran embajador de los cantes alosneros.

El Cerro de Andévalo, además de poseer una preciosa "folia", bailada por los llamados "danzaores", cuenta además con unos cantes, llamados "del camino", que se dedican a su patrón, San Benito Abad, el día de su romeria, además de otro, conocido como "toná de quintos" y un cadencioso fandango, que es cantado para el baile de "las jamugueras", solamente en solitario, acompañado por guitarra, o en su primera mitad en solitario interviniendo un coro en sus tres últimos tercios.

La procedencia del fandango de Santa Bárbara de Casa es casi desconocida por los actuales habitantes del lugar. Cierto es que, en el año 1946, el entonces famoso cantaor, Canalejas de Puerto Real, lo da a conocer en una grabación como tal estilo $y$, desde entonces, se le atribuye a esta localidad andevaleña. Además del citado fandango, se canta una antigua "jotilla" y se hace una danza llamada "el baile de la sonaja".

También existe una incógnita sobre el fandango atribuido a la localidad de Cabezas Rubias, estilo que se canta en la romeria a su patrón, San Sebastián, que tiene lugar en el mes de enero. 


\section{0 - 041 \\ Información del PH}

E I patrimonio minero andaluz. El futuro de un pasado

\section{PH45 - Octubre 2003}

tanto en criterios de difusión como de viabilidad económica y rentabilidad social (AGUILAR, I., 2001).

Sin duda, el ejemplo más destacado en el panorama andaluz es el onubense Museo Minero de Ríotinto (creado en 1992), un amplio proyecto (AGUILERA, E., 2001) del que tenemos abundante información en este mismo boletín.

Definitivamente cerrado en 1991, el coto minero de Linares presenta en su misma amplitud y diversidad graves problemas de conservación y gestión.

Destaca del conjunto de instalaciones (fundición de "San Luis" o los complejos de San Miguel, con el pozo más profundo de la Península, "La Cruz", "La Minera", Los Arrayanes"...) un elemento excepcional: la única instalación de bombeo general (llamada "casa bull"), para desagüe de las galerías, conservada en la Península.

Una reciente iniciativa, encabezada por el colectivo "Arrayanes", pretende habilitar una ruta (con una extensión total de 58 kilómetros) para visitar las 130 instalaciones mineras inventariadas que se conservan en Linares y municipios próximos (Bailén, La Carolina, Guarromán y Vilches). Se tiene previsto levantar un "Centro de Interpretación de la Metalurgia", que recoja la importancia de la extracción de galena argentifera para la comarca entre 1875 y 1930, periodo en el que fue (junto al coto minero de Cartagena-La Unión) el mayor productor europeo (MORENO, A., 2001).

Mayores problemas de gestión presentan las minas de Alquife, en la vertiente septentrional de sierra Nevada (Granada), pues, mientras un colectivo de intelectuales y vecinos han solicitado su
6. La "Casa Carreño", antigua fundición de Heredia en Adra (Almería), hoy desaparecida

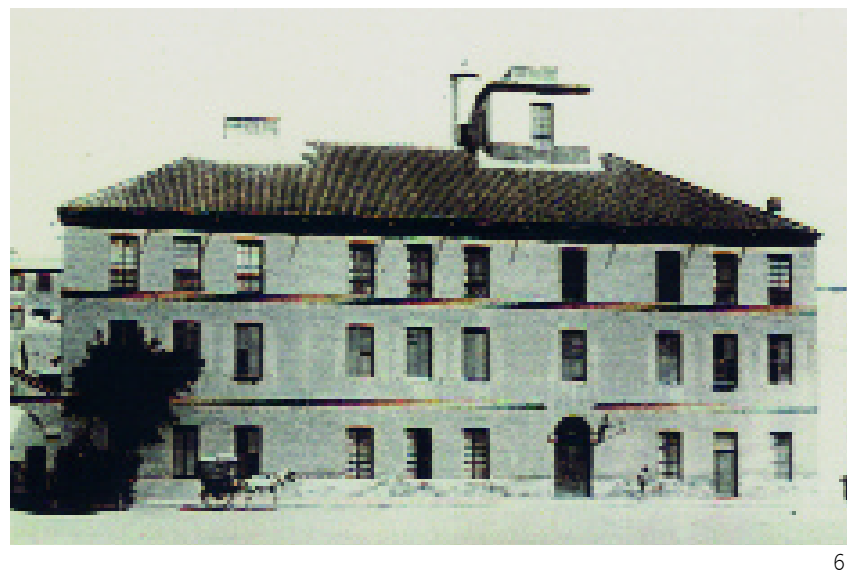

declaración como Bien de Interés Cultural (BIC) y Punto de Interés Geológico (PIG), la empresa propietaria mantiene diversos contactos para crear un "parque arqueológico industrial", todavía de contenido bastante inconcreto.

Carácter más medioambiental adquirió la rehabilitación por la Consejería de Obras Públicas hace unos diez años de parte de los edificios de Las Menas de Serón (Almería), coto minero cerrado en 1968 (ESPINOSA, J. y MENA, P., 1997).

El resto de las iniciativas (GIL, L., 1994 y SOBRINO, J., 2001) mantienen un carácter local y dependen para su desarrollo, consecución y mantenimiento de la buena voluntad de los propietarios y, sobre todo, de la inversión obtenida de entidades locales y de los fondos regiones europeos de desarrollo para áreas rurales.

Por último, tenemos el fandango atribuido al pueblo minero de Riotinto. Un estilo discutido ya que los valverdeños se lo apropian como lugar de nacimiento. Lo cierto es que, en 1974, lo graba el aficionado de La Palma del Condado, Miguel Pichardo, registrando el mismo como fandango de Riotinto.
Valverde del Camino posee un estilo de fandango valiente y muy musical, popularizándolo con exacta cuadratura un carnicero, hijo del lugar, llamado Ildefonso Romero, conocido históricamente como "El Gatillo".

El estilo -o estilos- de la localidad de Zalamea la Real viene de antiguo. Es este un fandango que se puede hacer de diferentes maneras, ya que son muchas la variantes que admite dentro de la misma estructura musical. Estilo que, para bailar, no se canta y es sólo acompañado por guitarras, bandurrias y panderetas. 


\section{Bibliografía}

AGUILAR CIVERA, I. (2001) La investigación sobre el Patrimonio Industrial. Una revisión bibliográfica. Rev. TST, $n^{\circ}$ 1, 2001, pp. 169-86. Ed. electrónica: http://www.tstrevista.com/descargas/dossier7.pdf [consulta: 08/06/2003]

AGUILERA COLLADO, E. (2001) El Museo Minero: un proyecto progresivo de re cuperación. En Preservación de la arquitectura industrial en Iberoamérica y España. Cuadernos del IAPH, ${ }^{\circ}$ XII, 2001, pp. 256-74

AMORES CORREDANO, F y LLORET MARÍN, T. (1995) Un lote de crisoles triangulares modernos en Sanlúcar de Barrameda. SPAL, nº 4, 1995, pp. 265-272

ARQUEOLOGÍA INDUSTRIAL. (1991) Actes del I Congrés del Pais Valenciá. Col. Estudios de Historia Local, n 7, Valencia: Diputación Valenciana, 1991

ARRIBAS, A. CRADDOCK, P., MOLINA, F. y ROTHEMBERG, B. (1989) Investigación arqueometalúrgica en yacimientos de las Edades del Cobre y Bronce en el Sudeste de Iberia. En Mineria y Metalurgia en las antiguas civilizaciones mediterráneas y europeas. Madrid, I, 1989, pp. 71-80

BERNÁRDEZ GÓMEZ, Mํㅗㄹ J., GUISADO DI MONTI J. C. y RUIZ CARMONA, S. (1996) Cuatro candiles inéditos de Rio Tinto en el Museo de la escuela de Minas de Madrid: nuevos datos para el conocimiento de la minería musulmana en la zona. En Actas de las I Jornadas sobre minería y tecnología en la Edad Media peninsular. León, 1996, pp. 162-179

BERTRAND, M., SÁNCHEZ VICIANA, J.R. y ZUBIAUR MARCOS, J.F. (1996) Mines et métallurgies médiévales de la Sierra Nevada (Région de Guadix, Prov. de Grenade). Premieres données. En Actas de las I Jornadas sobre mineria y tecnología en la Edad Media peninsular. León, 1996, pp. 180-197

BLANCO-FREJEIRO, A. y LUZÓN, J. Mạ . (1966) Mineros antiguos españoles. En Archivo Español de Arqueología, $n^{\circ}$ 39, 1966, pp. 73-88

BLANCO-FREJEIRO, A. y ROTHEMBERG, B. (1981) Exploración arqueometalúrgica de Huelva. Barcelona, Labor-Rio Tinto Minera, 1981. ROTHEMBERG, B. y BLANCO-FREJEIRO, A. Ancient Mining and Metallurgy in South-East Spain. Londres: Institute for Archaeo-Mettallurgical Studies, 1981

BOSCH GIMPERA, P. y DE LUXAN, F. (1935) Explotación de yacimientos argentiferos en el Eneolítico, en Almizaraque (prov. de Almeria). En Investig. y Progreso, $n^{\circ}$ IX, 1935, pp. 112-117

BUCHANAN, R. A. (1977) Industrial Archaeology in Britain. Harmondsworth, 1977 (Primera edición, 1972)

CAPEL, H. (1955) El turismo industrial y el patrimonio histórico de la electricidad. En Jornadas sobre Catalogación del Patrimonio Histórico. Hacia una integración disciplinar. Sevilla, 1995. IAPH. Sevilla,1996, pp. 170-195 (edición electrónica: http://www.ub.es/geocrit/sv-14.htm) [consulta: 08/06/2003]

CARA BARRIONUEVO, L. y RODRÍGUEZ LÓPEZ, J. Mª (1986) Notas para el estudio de la minería almeriense anterior al siglo XIX. En Boletín del Instituto de Estudios Almerienses, $n^{\circ} 6$ L, 1986, pp. 11- 24

CARA B., L. (2000) Las herrerias del Andarax. Notas para el estudio de la minería alpujarreña en los siglos XVI a XVIII. En Farua, n³ 3, Sevilla, 2000, pp. 95-104

CARA B., L. (2002) La mineria de Sierra de Gádor, nuestro legado. Colección Patrimonio de la Alpujarra n 1 . Almería, 2002
CARANDINI, A. (1984) Arqueología y cultura material. Barcelona: Mitre, 1984

CARANDINI, A. (1997) Historias en la tierra. Manual de excavación arqueológica. Barcelona: Crítica-Arqueología, 1997

CATALOGACIÓN del Patrimonio Histórico (1996). Actas de las I Jornadas sobre Catalogación del Patrimonio Histórico. Hacia una integración disciplinar. Sevilla, 1995, Sevilla. IAPH, Sevilla, 1996

COHEN, A. (1987) El Marquesado de Zenete, Tierra de Minas. Granada: Diputación de Granada, 1987

COHEN, A. (2002) Minas y mineros de Granada (siglos XIX y XX). Granada: Diputación de Granada, 2002

COLECCIÓN legislativa de minas, 3 vols. Madrid, 1889, 1890 y 1892

CHECA, Fr. (1995) Labradores, pastores y mineros en el Marquesado del Zenete. Una monografía antropológica sobre Lanteira (Granada) (1890-1960). Granada, 1995

DOCUMENTACION para la inscripción colectiva en el Catálogo General de Patrimonio Histórico de Andalucia, con carácter genérico, de los elementos industriales de interés arqueológico relacionados con la actividad minera en la provincia de Almería (2000). Eugenio Cifuentes Vélez y Jaime López Gómez, con la colaboración de Baltasar Martínez Portillo. Trabajo encargado por la Delegación prov. de Cultura de la Junta de Andalucía. Almería, 13-XII-2000 (Mecanografiado). En la actualidad se tiene previsto ampliar esta documentación a otras provincias.

DOMERGUE, C. (1987) Catalogue des Mines et Fonderies Antiques de la Peninsule Iberique. 2 vols, Madrid: Casa de Velázquez, 1987

DOMERGUE, C. (1993) Les Mines de la Peninsule Iberique dans l'Antiquité Romaine. Roma, 1993

ESPINOSA CABEZAS, J. y MENA ENCISO, P. (1997) Minas de Hierro de Serón. Almeria: Inst. Est. Almer., 1997

FLORES, M. (1983) Río Tinto. La fiebre minera del XIX. Huelva: Instituto de Estudios Onubenses Padre Marchena, 1983

FRANCO SILVA, A. (1996) El alumbre del Reino de Murcia. Una historia de ambición, intrigas, riqueza y poder. Murcia, 1996

FRANCOVICH, R. (coord.) (1993) Archeologie delle attività estrattive e metallurgiche. Firenze, 1993 y (1996) Per una storia sociale delle attività estrattive e metallurgiche: a proposito di alcune recenti richerche archeologiche nella Toscana mineraria del medioevo. En Actas de las I Jornadas sobre mineria y tecnología en la Edad Media peninsular. León, 1996, pp. 19-35

FRANCOVICH, R. y MANACORDA, D. (eds.) (2001) Diccionario de arqueología. Barcelona: Crítica-Arqueología, 2001

GIL VARÓN, L. (1984) Río Tinto. Papeles Socioeconómicos de una Gran Mina Andaluza en Régimen Colonial. Huelva, 1984

GIL VARÓN, L. (1994) Arqueología minera de Los Pedroches. En $1^{a}$ Jornadas Ibéricas del Patrimonio Industrial y de la Obra Pública. Sevilla-Motril, 1990. Sevilla: Consejería de Cultura, 1994, pp. 377-83

GÓMEZ MARTíNEZ, J.A. y COVAS NAVARRO, J.V. (1994) Trenes, cables y minas de Almeria. Almería: Instituto de Estudios Almerienses, 1994 


\section{$042-043$ \\ Información del PH \\ E I patrimonio minero andaluz. El futuro de un pasado \\ PH45 - Octubre 2003}

GÓMEZ RAMOS, P. (1997) Historiografía de la arqueometalurgia en España. En Boletín de la Asociación Española de Amigos de la Arqueologia, n 37, 1997, pp. 139-150

GONZÁLEZ, T. (1832) Registro y relación general de minas de la corona de Castilla. 2 t. Madrid, 1832

GONZÁLEZ-MORENO NAVARRO, A. (1994) Reutilización del patrimonio industrial. En $1^{\text {a }}$ Jornadas Ibéricas del Patrimonio Industrial y de la Obra Pública. SeviIla-Motril, 1990. Sevilla: Consejería de Cultura, 1994, pp. 419-24

HUDSON, K. (1964) Industrial Archaeology. An Introduction. Londres, 1964

IZARZUGAZA LIZARRAGA, I. y OLAIZOLA ELORDI, J. J. (1994) Inventario del patrimonio industrial en España: una aproximación al estado de la cuestión. En $1^{\text {a }}$ Jornadas Ibéricas del Patrimonio Industrial y de la Obra Pública. Sevilla-Motril, 1990. Sevilla: Consejería de Cultura, 1994, pp. 3-61

LÓPEZ, T. (1985 y 1990) Diccionario geográfico de Andalucia: Almeria. Ed. y est. de SEGURA, Cr. Almeria: Instituto de Estudios Almerienses, 1985 y Diccionario geográfico de Andalucia: Granada. Sevilla, 1990

MADOZ, P. (1845-1850) Diccionario geográfico-estadistico-histórico de España y sus posesiones de ultramar. Madrid, 1845-1850. Edic. Facsimil de cada una de las provincias andaluzas: 1986 (Cádiz, Málaga y Sevilla), 1987 (Córdoba y Granada) y 1988 (Almería, Huelva y Jaén)

MARTínEZ MARÍN, A. (1985) Arqueología industrial en Almeria. Guía de la Exposición. Almería: Instituto de Estudios Almerienses, 1985

MONTERO RUIZ, I. (1992 y 1994) Estudio Arqueometalúrgico en el Sudeste de la Península Ibérica. Colección Madrid: Universidad Complutense, Tesis Doctoral, 1992 y El origen de la metalurgia en el Sudeste de la Peninsula Ibérica. Almeria: Instituto de Estudios Almerienses. Colección de Investigación 19, 1994

MORA PIRIS, P. (1994) La Real Fundición de bronces de Sevilla, ejemplo de arqueología industrial dieciochesca. En $1^{\text {a }}$ Jornadas Ibéricas del Patrimonio Industrial y de la Obra Pública. Sevilla-Motril, 1990. Sevilla: Consejería de Cultura, 1994, pp. 663-68

MORALES SÁNCHEZ, R. y GAGO VÁZQUEZ, A. (coord.) (2001a) El patrimonio industrial. El Cable Inglés de Almeria. Almeria: Instituto de Estudios Almerienses, 2001 y (2001b) Arqueologia industrial y entorno urbano: reflexiones sobre la recuperación del Cable Inglés de Almeria. En Preservación de la arquitectura industrial en Iberoamérica y España. Sevilla: Cuadernos del IAPH, $n^{\circ} \mathrm{XII}$, 2001, pp. 318-28

MORENO RIVILLA, A. (2001) Un proyecto para la valorización de los vestigios mineros e industriales de Linares. En Preservación de la arquitectura industrial en Iberoamérica y España. Sevilla: Cuadernos del IAPH, nº XII, 2001, pp. 297

NADAL, J. (1972) Industrialización y desindustrialización del Sureste español, 1817-1913. En Moneda y Crédito n²120, 1972, pp. 3-80

OREJAS, A., PLÁCIDO, D., SÁNCHEZ-PALENCIA, F. J. y FERNÁNDEZPOSSE, Ma D. (1999) Minería y metalurgia. De la protohistoria a la España romana. En Stvd. Hist., $H^{\text {a }}$ Antig., ${ }^{\circ}$ 17, 1999, pp. 253-298

PÉREZ, J. A. Metalurgia Extractiva Prerromana en Huelva. Huelva: Servicio de Publicaciones de la Universidad, 1996

PÉREZ DE PERCEVAL VERDE, M. A. (1985) Fundidores, mineros y comerciantes. La metalurgia de Sierra de Gádor, 1820-1850. Almería, 1985
RAMíREZ COPEIRO, J. (1985) Ingleses en Valverde. Aspecto Humano de la Mineria Inglesa en la Provincia de Huelva. Huelva, 1985

RAMOS, A., MARTÍNEZ, G., RÍOS, G., GARCÍA, A., JABALOY, A. y ERIGARAY, C. (1991) La Venta flint mine (Southeast Spain). A report on integrated Geoarchaeology in field methodology. En Abstracts del VI Symposium del Sílex, (MadridBilbao-Granada 1991). Madrid, 1991, pp. 170-173

RUIZ GARCíA, A. (2001) Arqueología industrial almeriense: memoria histórica, recursos didáctico y potencialidad turistica. En MORALES, R. y GAGO, A., (eds.). Actas del Seminario El Cargadero de mineral. Una apuesta de futuro. En El patrimonio industrial. El Cable Inglés de Almería. Almeria: Instituto de Estudios Almerienses, 2001, pp. 13-33

SÁNCHEZ GÓMEZ, J. (1989) De mineria, metalúrgica y comercio de metales. La minería no férrica en el Reino de Castilla, 1450-1610. 2 vols. Salamanca, 1989

SÁNCHEZ PICÓN, A. (1983) La minería del levante almeriense, 1838-1930. Especulación industrialización y colonización económica. Almería, 1983

SÁNCHEZ PICóN, A. (coord.) (1991) El siglo minero. Imágenes de una Almería del siglo XIX. Almeria: Instituto de Estudios Almerienses, 1991

SÁNCHEZ PICÓN, A. (1996) La presión humana sobre el monte en Almeria durante el siglo XIX. En SÁNCHEZ P., A, (ed.) (1996) Historia y medio ambiente en el territorio almeriense. Almería: Univ. de Almería, 1996, pp. 169-202

SIRET, H. y L. (1887) Les Premiers Âges du Métal dans le sud-est de l'Espagne. Amberes, 1887 (traducc. española. Barcelona, 1890)

SOBRINO SIMAL, J. (1994) El impacto medioambiental del desarrollo tecnológico en la historia de España. En $1^{\text {a }}$ Jornadas Ibéricas del Patrimonio Industrial y de la Obra Pública. Sevilla-Motril, 1990. Sevilla: Consejeria de Cultura, 1994, pp. 235-41

SOBRINO, J. (2001) El complejo minero de Villanueva del Río y Minas. En El Patrimonio Industrial en Andalucia. Sevilla: Consejería de Cultura, 2001, pp. 143-149

TICCIH [Comisión Internacional para la Conservación del Patrimonio Industrial] (1995) VIII Congreso Internacional para la Conservación del Patrimonio Industrial. Madrid: Ministerio de Obras Públicas y Urbanismo-CEHOPU, 1995

TOMÁS GARCíA, L. (1994) La campaña de protección del patrimonio tecnológico de Andalucía en el programa de Juventud y Cultura de la Junta de Andalucía. En $1^{\text {a }}$ Jornadas Ibéricas del Patrimonio Industrial y de la Obra Pública. Sevilla-Motril, 1990. Sevilla: Consejería de Cultura, 1994, pp. 521-24

THOMPSON, P. (1988) La voz del pasado. Historia oral. Valencia, 1988

TORRÓ, J. (1994) Arqueologia, trabajo y capital. En Sociología del Trabajo, n²2, 1994, pp. 47-62

VALLVE BERMEJO, J. (1996) La mineria en Al-Andalus. En Actas de las I Jornadas sobre minería y tecnología en la Edad Media peninsular. León, 1996, pp. 56-64 